\title{
Erratum to: Genetic variability and haplotype profile of $M D R I$ in Saudi Arabian males
}

\author{
Abdullah M. Al-Mohizea $\cdot$ Khalid M. Alkharfy $\cdot$ Khawla M. Bagulb • \\ Amal M. Alghamdi · Fahad I. Al-Jenoobi · Saleh Al-Muhsen · Rabih Halwani • \\ Mohammad Khalid Parvez • Mohammed S. Al-Dosari
}

Published online: 11 November 2012

(C) Springer Science+Business Media Dordrecht 2012

Erratum to: Mol Biol Rep (2012) 39:10293-10301

DOI 10.1007/s11033-012-1906-3

This erratum is published as one of the author's surname was incorrectly published.

Mohammad Khalid Parvez should be read as M. K. Parvez.

The online version of the original article can be found under doi:10.1007/s11033-012-1906-3.

A. M. Al-Mohizea · F. I. Al-Jenoobi

Department of Pharmaceutics, College of Pharmacy,

King Saud University, Riyadh, Saudi Arabia

K. M. Alkharfy

Department of Clinical Pharmacy, College of Pharmacy,

King Saud University, Riyadh, Saudi Arabia

K. M. Alkharfy

Biomarkers Research Program, College of Pharmacy,

King Saud University, Riyadh, Saudi Arabia

K. M. Bagulb - A. M. Alghamdi - S. Al-Muhsen - R. Halwani Department of Pediatrics, Asthma Research Chair and Prince Naif Center for Immunology Research, College of Medicine,

King Saud University, Riyadh, Saudi Arabia

M. K. Parvez · M. S. Al-Dosari ( $\square)$

Department of Pharmacognosy, College of Pharmacy, King Saud University, P.O. Box 2457, Riyadh 11451, Saudi Arabia

e-mail: msdosari@yahoo.com 